\title{
EFEITO DO BIOPESTICIDA À BASE DE Bacillus thuringiensis EM MINHOCAS (Eisenia andrei): ENSAIO DE COMPORTAMENTO DE FUGA
}

Effect of the Bacillus thuringiensis-based biopesticide on earthworms (Eisenia andrei): behavior avoidance test.

Efecto del bioplaguicida basado en Bacillus thuringiensis en lombrices de tierra (Eisenia andrei): Prueba de comportamiento de evitación.

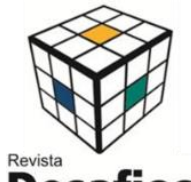

\section{Desafios}

Artigo Original

Original Article Artículo Original

\section{Ieda Regina Ajalla Ichihara ${ }^{1}$, Marcelo Gustavo Paulino ${ }^{1 *}$}

${ }^{1}$ Laboratório Morfofisologia Animal Comparada, Curso de Biologia, Universidade Federal do Tocantins, Araguaína, Brasil.

*Correspondência: Coordenação do curso de Biologia-Licenciatura, Universidade Federal do Tocantins Campus Araguaína, Av. Paraguai s/n, Araguaína, Tocantins, Brasil. CEP: 77.824-838 . e-mail: marcelopaulino@uft.edu.br

\section{RESUMO}

Pesticidas sintéticos são normalmente utilizados de maneira excessiva nas lavouras e vem provocando diversas alterações nos ecossistemas terrestres, particularmente em espécies nativas não-alvos. Uma maneira de amenizar estes impactos é a substituição destes agroquímicos por pesticidas biológicos. O biopesticida mais utilizado para este fim vem sendo os formulados à base de esporos de Bacillus thuringiensis, uma bactéria gram-negativa que é seletivamente danosa para alguns insetos. O presente trabalho teve como objetivo aplicar um ensaio ecotoxicológico comportamental em solo, utilizando anelídeos, testando a qualidade do solo e níveis de toxicidade após exposição aguda. As minhocas ( $\mathrm{n}=10$, oito réplicas) foram expostas em terrário $\left(30 \mathrm{~cm}^{2}\right)$ simultaneamente em amostras de solo controle (sem o biopesticida) e solo contaminado (com biopesticida) na concentração de $0,005 \mathrm{~g} / \mathrm{cm}^{2}$. Após a exposição os organismos foram contados em cada solo respectivo e a porcentagem de evitamento foi calculada. Após $48 \mathrm{~h}$ de exposição, não houve mortalidade ou sinais de toxicidade do biopesticida na morfofisiologia dos animais. $\mathrm{O}$ teste de fuga indicou evitamento negativo, o que sugere que o biopesticida contendo $B$. thuringiensis pode ser inerte para estes importantes decompositores e uma alternativa menos drástica ao ecossistema, uma vez aplicado à lavoura.

Palavras-chave: Dipel, ecotoxicologia terrestre, anelídeos.

\section{ABSTRACT}

The synthetic pesticides is used excessively in crops and has been causing several changes in terrestrial ecosystems, particularly in native non-target species. One way to mitigate these impacts is to replace these agrochemicals with biological pesticides. The most biopesticide used for this purpose has been the spore-based formulations of Bacillus thuringiensis, a gram-negative bacterium that is selectively harmful to some insects. The present work aimed to apply a behavioral ecotoxicological test on soil, using annelids, testing the soil quality and toxicity levels after acute exposure. Earthworms ( $n=10$, eight replicates) were exposed in terrarium $\left(30 \mathrm{~cm}^{2}\right)$ simultaneously in samples of control soil (without the biopesticide) and contaminated soil (with biopesticide) at a concentration of $0.005 \mathrm{~g} / \mathrm{cm}^{2}$. After exposure, the organisms were counted in each respective soil and the percentage of avoidance was calculated. After 48 h of exposure, there was no mortality or signs of toxicity of the biopesticide in the morphophysiology of the animals. The avoidance test indicated negative values, which suggests that the B. thuringiensis biopesticidecontaining may be inert for these important decomposers and a less drastic alternative to the ecosystem, once applied to crops.

Keywords: Dipel, terrestrial ecotoxicology, annelids. 


\section{RESUMEN}

Pesticidas sintéticos se usa normalmente en exceso en los cultivos y ha estado causando varios cambios en los ecosistemas terrestres, particularmente en especies nativas no objetivo. Una forma de mitigar estos impactos es reemplazar estos agroquímicos con pesticidas biológicos. El biopesticida más utilizado para este propósito ha sido las formulaciones a base de esporas de Bacillus thuringiensis, una bacteria gramnegativa que es selectivamente dañina para algunos insectos. El presente trabajo tuvo como objetivo aplicar una prueba ecotoxicológica conductual en el suelo, usando anélidos, probando la calidad del suelo y los niveles de toxicidad después de una exposición aguda. Las lombrices de tierra $\left(n=10\right.$, ocho réplicas) fueron expuestas en terrario $\left(30 \mathrm{~cm}^{2}\right)$ simultáneamente en muestras de suelo control (sin el biopesticida) y suelo contaminado (con biopesticida) a una concentración de 0.005 $\mathrm{g} / \mathrm{cm}^{2}$. Después de la exposición, se contaron los organismos en cada suelo respectivo y se calculó el porcentaje de evitación. Después de 48 h de exposición, no hubo mortalidad ni signos de toxicidad del bioplaguicida en la morfofisiología de los animales. La prueba de fugas indicó una evitación negativa, lo que sugiere que el biopesticida que contiene B. thuringiensis puede ser inerte para estos descomponedores importantes y una alternativa menos drástica al ecosistema, una vez aplicado a los cultivos.

Descriptores: Dipel, ecotoxicología terrestre, anélidos.

\section{INTRODUÇÃO}

A contaminação por agrotóxicos em ambientes terrestres tem sido comum nas últimas décadas, resultando em efeitos tóxicos principalmente para a fauna silvestre e doméstica, além de causar danos ao ambiente. Entretanto, a demanda de agroquímicos promove um aumento da produção com aumento consequente da poluição (Céspedes e Alarcon, 2011). Cada pesticida, com sua formulação específica, atende um mecanismo de ação próprio no qual eliminam pragas da lavoura, e assim, são divididos em classes, das quais as principais são inseticidas, herbicidas e fungicidas (Modesto, 2009).

As vias de aplicação dos pesticidas incluem principalmente as pulverizações, no qual podem se espalhar pela ação do vento para locais próximos como hortaliças, corpos d'água e centros urbanos próximos. Assim alternativas menos danosas, como o controle biológico tem sido uma alternativa. Os bioinseticidas são alternativas ecológicas e sustentáveis para manter o equilíbrio do ecossistema (Almeida et al., 2009).

O mais sucedido inseticida biológico para controle de pestes é a bactéria Bacillus thuringiensis (Bt), da qual são exclusivamente ativas contra larvas de diferentes ordens de insetos, matando-os por desregulação da morfofisiologia do trato gastrointestinal, seguido de septicemia (Raymond et $a l .$, 2010). Biopesticidas à base de Bt são considerados inertes à organismos que não são alvos específicos. Com base nisso, o biopesticida tem sido amplamente utilizado na lavoura como um inseticida alternativo (Mariano, 2017).

A complexidade ambiental exige geralmente priorizar processos de degradação, buscando soluções e mecanismos que tenham como foco as possíveis causas que possam compreender o processo na sua evolução. A preservação do solo, assim como da água, é de fundamental importância para a utilização dos recursos domésticos e agrícolas, assim como para a biota local (Adams, 2002). O solo, sendo um sistema vivo e complexo, depende de bilhões de organismos, como as bactérias, protozoários, fungos, vermes, aracnídeos, pequenos insetos e, de maneira substancial, os anelídeos.

As minhocas representam entre 40 a $90 \%$ da biomassa de macrofauna do solo em ambientes tropicais e sua importância na formação estrutural do solo, decomposição de resíduos, ciclagem de nutrientes, formação de humos é imensurável. Com base nisso, é reconhecido a importância destes 
anelídeos como bioindicadores-sentinelas nas informações sobre biodisponibilidade dos poluentes e sua contaminação (Andréa, 2010).

Ensaios comportamentais com anelídeos em estudos ecotoxicológicos de ecossistemas terrestres tem demonstrado um método rápido para verificar a de substâncias químicas no solo, no qual o comportamento de fuga pode ser utilizado como um excelente bioindicador (ISO, 2008). O ensaio visa expor organismos simultaneamente a solos com presença ou não do biopesticida em seções distintas formando dois comportamentos e, ao final da exposição, determinar se a amostra é tóxica e verificar se a função de habitat do solo se torna limitada e menos produtiva (Sisinno et al., 2006).

A fim de obter uma melhor compreensão do mecanismo do Bt no solo e seus efeitos em organismos não-alvos, no presente trabalho nós objetivamos aplicar um ensaio ecotoxicológico comportamental em solo, utilizando anelídeos como indicadores, testando a qualidade do solo e níveis de toxicidade após exposição aguda.

\section{MATERIAIS E MÉTODOS}

\section{Organismos e contaminante}

Exemplares de minhocas da espécie Eisenia andrei (massa corpórea 0,405 \pm 0,02 g e comprimento de $8,1 \pm 0,51 \mathrm{~cm}$ ) foram obtidas em um produtor local na cidade de Araguaína - Tocantins, Brasil. Os animais foram levadas para o Laboratório de Morfofisiologia Animal Comparada (LaMAC multiuso) da Universidade Federal do Tocantins, campus Cimba onde foram aclimatadas durante 07 dias em substrato preparado pelo produtor, onde os parâmetros seguidos foram: umidade entre 70 e $85 \%$, temperatura entre $23 \pm 2^{\circ} \mathrm{C}, \mathrm{pH} 7,0$, fotoperiodo natural (luz constante) e alimentação com produtos orgânicos de origem animal ou vegetal semicurado (livre de fermentação), segundo a ISO 1 1268-2 (ISO, 1993).

O biopesticida aplicado para o teste foi a fórmula comercial do $\mathrm{DiPel}^{\circledR} \mathrm{WP}$ contendo como princípio ativo esporos de Bt var. Kurstaki, linhagem HD-1, mínimo de 25 bilhões de esporos viáveis por grama de produto, registrado no Ministério da Agricultura, Pecuária e Abastecimento (MAPA) sob o $\mathrm{n}^{\circ} 00858901$ e pertencente à classe dos inseticidas biológicos, de ingestão (ADAPAR, 2018).

\section{Delineamento experimental para os testes fuga.}

$\mathrm{O}$ solo natural utilizado no ensaio ecotoxicológico, foi coletado em área rural distante 30 km da cidade de Araguaína, Tocantins, Brasil. O ponto amostral da coleta foi escolhido aleatoriamente distante de zona de plantio. A coleta aconteceu com a remoção da camada superior do solo e na profundidade de 20 a $30 \mathrm{~cm}$ da superfície com auxílio de uma pá cavadeira (Chini, 2014).

O solo foi ajustado em relação a sua capacidade de retenção de água (CRA) para os bioensaios segundo norma da ISO 11268-2 (ISO, 1998) com umidade em $45 \%$ da CRA. Em solo natural recomenda-se não fazer ajuste de $\mathrm{pH}$, entretanto, o pH foi medido e estava dentro do recomendado (Niva, 2019).

A primeira etapa do delineamento experimental consistiu na preparação dos testes na confecção de terrários plásticos de $300 \mathrm{~cm}^{2}$ contendo uma divisória, de modo que ficasse dividido dois compartimentos de $150 \mathrm{~cm}^{2}$ contendo 700 gramas de solo em cada parte. A divisória do solo é para um deles conter o solo controle (livre de compostos) e o outro contém solo teste (com a presença de compostos), em conformidade com a norma ABNT NBR ISO 17512-1 (ABNT, 2011).

A segunda etapa do delineamento consistiu em realizar um teste com controle negativo (em duplicata) 
utilizando água destilada para umedecer o solo. Assim, as minhocas foram divididas em dois grupos $(n=10)$ e colocadas no centro da caixa-terrário de exposição (Figura 1). Após 48 horas a divisória foi recolocada para contagem dos indivíduos.

Figura 1. Caixa terrário desenvolvida para os testes de fuga.

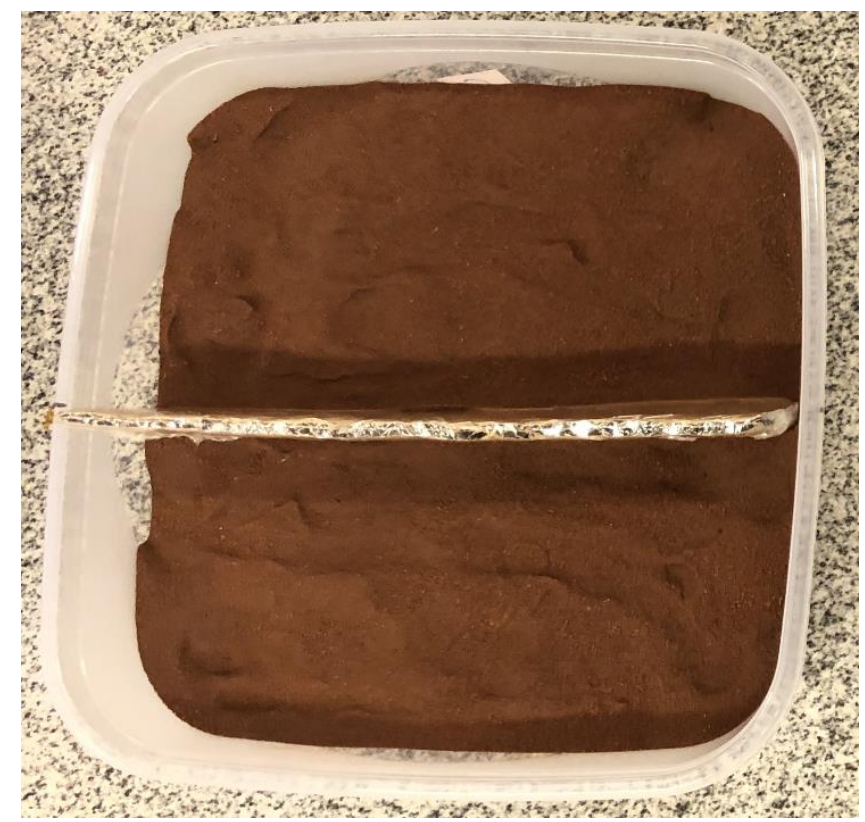

Em seguida foi realizado o teste de fuga com um controle positivo, utilizando $\mathrm{H}_{2} \mathrm{BO}_{3}$ (ácido bórico - AB) como substância referência (em duplicata) para verificar a sensibilidade do organismo teste. Para isso, as minhocas foram divididas aleatoriamente em grupos $(n=10)$ e colocadas no centro da caixa-terrário de exposição, após a remoção da divisória. Após 48 horas, a divisória foi recolocada para a contagem dos indivíduos em cada seção. Foram utilizadas três concentrações crescentes de ácido bórico (250; 750 e $1250 \mathrm{mg} \mathrm{kg}^{-1}$ de solo).

A última etapa do delineamento foi testar a qualidade do solo após aplicação do biopesticida. Para isso, as minhocas foram divididas em 8 grupos $(n=10)$. O compartimento com o solo teste recebeu o biopesticida na concentração de $0,005 \mathrm{~g} / \mathrm{cm}^{2}$, que simulou a concentração média do Dipel utilizada em algumas lavouras (ADAPAR, 2018). As minhocas foram colocadas no centro da caixa-terrário de exposição. Após 48 horas, a divisória foi recolocada para a contagem dos indivíduos.

A análise dos dados foi feita segundo a norma ABNT NBR ISO 17512-1 (ABNT, 2011), no qual calcula a porcentagem de organismos vivos no solo controle em relação ao número de indivíduos no solo teste, seguindo a fórmula: $\mathrm{E}(\%)=[(\mathrm{C}-\mathrm{T}) / \mathrm{N}] \mathrm{x} 100$. Onde, $\mathrm{E}=$ porcentagem de evitamento; $\mathrm{C}=$ soma dos indivíduos observados no controle (somando as repetições); $\mathrm{T}=$ soma dos indivíduos observados nos testes (somando as repetições); $\mathrm{N}=$ Soma dos indivíduos totais colocados nas repetições.

O projeto foi aprovado pelo comitê de uso de animais - UFT (CEUA) sob número 23101.001.738/2018-99.

\section{RESULTADOS E DISCUSSÃO}

As minhocas Eisenia fetida e Eisenia andrei, desempenham o papel de bioindicadores sensíveis e oferecem inúmeras possibilidades de estudos de contaminação ambiental tanto por agrotóxicos, como por metais, derivados do petróleo, antibióticos, produtos veterinários, e outros poluentes (Sisinno et al., 2006) e (Loureiro et al., 2005).

Ao final de todas as exposições não ocorreram mortes dos indivíduos. Após o teste do controle negativo, contendo apenas solo com água destilada (controle dual) os animais estavam distribuídos nas réplicas de maneira equitativa (Figura 2 ).

A ABNT (2011) estipula a validação ideal para o teste se dá quando um limiar de distribuição das minhocas fica ente $40 \%$ e $60 \%$ em cada lado do recipiente quando se trata da mesma composição do solo em ambas os compartimentos. Entretanto, um critério foi adotado na contagem dos resultados onde, considerava-se a localização da cabeça do animal. Portanto, o critério principal de validação para o composto e a espécie foi atendido e o ensaio validado, 
uma vez que as condições dos testes para exposição mostram adequação.

As concentrações da substância referência causaram resposta de fuga após exposição (Figura 3). $\mathrm{A}$ rejeição fuga ao solo com $\mathrm{AB}$ pôde gerar resposta positiva a partir de $250 \mathrm{mg} \mathrm{Kg}^{-1}$ de solo e obteve comportamento dose-dependente. Não houve mortalidade nos testes do presente estudo, entretanto, (Niemeyer et al., 2018) mostraram mortalidade em $\mathrm{CL}_{50}$ maior que $1.000 \mathrm{mg} \mathrm{kg}^{-1}$ de $\mathrm{AB}$ em solo artificial. Assim, esta substancia não seria recomendada para testes de mortalidade.

Figura 2. Ensaio do controle negativo (controle dual). Porcentagem da frequência de indivíduos em cada seção do terrário de exposição. Teste em duplicada, $n=10$ por réplica.

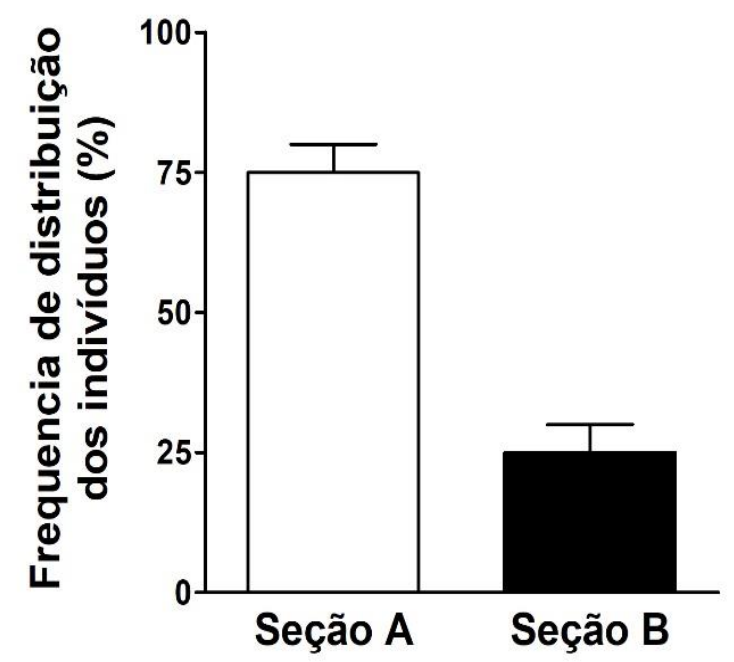

Figura 3. Ensaio do controle positivo (substância referência - ácido bórico). Porcentagem da frequência de indivíduos em cada seção do terrário de exposição. Teste em duplicada, $\mathrm{n}=10$ por réplica.

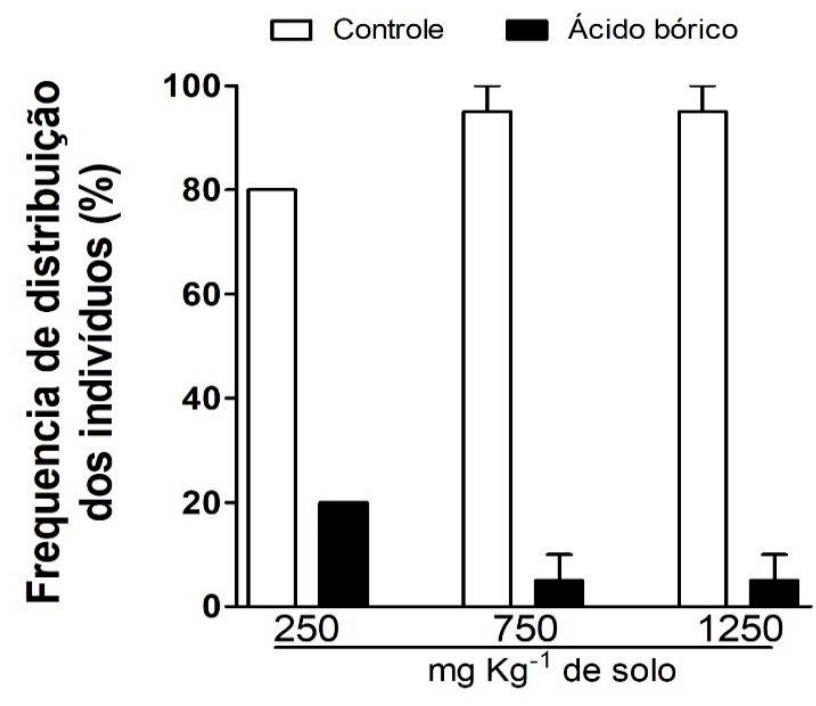

Quando se trata em teste de fuga, o AB é uma substancia recomendada (ISO, 2014). Após exposição, e evasão (fuga) ao solo com $\mathrm{AB}$ pode ser atribuída a reação fisiológica do animal e à rejeição tóxica do composto de conformidade com (Candello, 2014) e (Princz e Scroggins, 2003).

A resposta de fuga calculada em termos de porcentagem de evitamento pela concentração de Bt testada foi feita segundo fórmula proposta pelas normativas (ABNT, 2011) para solo SAT e solo natural, e está representada na Tabela 1.

Tabela 1. Porcentagem de evitamento por Eisenia andrei após exposição por $0,005 \mathrm{~g} / \mathrm{cm}^{2}$ do biopesticida utilizado para contaminação do solo natural do teste agudo de fuga.

\begin{tabular}{lc}
\hline $\begin{array}{c}\text { Disposição dos indivíduos nos } \\
\text { compartimentos }\end{array}$ & $\begin{array}{c}\text { Número de } \\
\text { indivíduos }\end{array}$ \\
\hline Controle & 38 \\
Solo natural com Bt $(0,005$ & 44 \\
$\left.\mathrm{~g} / \mathrm{cm}^{2}\right)$ & \\
\hline Comportamento de fuga & $-7,2 \%$ \\
\hline
\end{tabular}

A concentração do Bt utilizada neste estudo tange a média de Bt preparado para aplicação na lavoura, sendo assim considerada ecologicamente relevante. Nossos resultados sugerem que o solo com Bt, após uma aplicação, não causa interferência para a sobrevivência dos indivíduos. Sendo assim, se não houve fuga dos indivíduos em $48 \mathrm{~h}$ do solo Revista Desafios -v. 7, Especial - PIBIC, 2020 
contaminado para o controle, não pode ser considerado impróprio para sobrevivência, desenvolvimento e reprodução. Segundo a (ISO, 2008) e ABNT 17512-1 (ABNT, 2011), se houver a constatação de mortalidade ou se houver $80 \%$ ou mais do número de organismos no solo-controle, este é determinado como tóxico e tendo a sua função de habitat limitada.

Mesmo não havendo relatos na literatura sobre os efeitos tóxicos diretos a anelídeos e a outros invertebrados não-alvo pelo Bt, não se pode excluir a possibilidade de efeitos indiretos espécie-específica (Candello, 2014). Por outro lado, muitas espécies de Bacillus são importantes pois têm habilidades de produzir metabolitos antibióticos (ação probiótica) na qual age contra efeitos de outros microrganismos patogênicos (Kuebutornye et al., 2019). Não é claro a ação do Bt a outros organismos, entretanto, apesar de efeitos benéficos dos Bacillus sp., sabe-se que poucas espécies, incluindo a $B$. thuringiensis, são produtoras de toxinas, como as proteínas Cry, responsáveis pelos efeitos em lepidópteras (Elshaghabee et al., 2017).

No Brasil o ensaio de comportamento não é muito utilizado apesar de ser um método rápido e eficaz para averiguar a disponibilidade de agentes tóxicos no solo e poder ser usado por bioindicadores como Eisenia sp. (ISO, 2008; Sisinno et al., 2006). O teste de fuga aplicado neste estudo mostra-se de extrema importância para o entendimento dos efeitos do Bt no solo. Após à exposição aguda com biopesticida, constatou-se que o solo não tem porcentagem de função limitada, representada pelo comportamento negativo dos organismos.

\section{CONCLUSÃO}

Após a exposição ao Dipel podemos concluir que as minhocas do gênero Eisenia são bioindicadores sensíveis que possibilitam estudos de contaminação ambiental por apresentarem sensibilidade quando em presença de contaminantes tóxicos, ou a inocuidade dos mesmos, sendo a espécie $E$. andrei um eficaz bioindicador de qualidade solo para o Bacillus thuringiensis.

O Bt não influenciou o comportamento de evasão dos organismos na concentração testada, demonstrando que em testes agudos não interfere nas características físico-químicas do solo e, portanto, como perigo potencial para a mortalidade $\mathrm{e}$ sobrevivência dos animais.

\section{AGRADECIMENTO}

Os autores agradecem ao Dr. Wagner dos Santos Mariano pela doação do Dipel ${ }^{\circledR}$ e a técnica Luanne Pereira Gonçalves pela ajuda no laboratório. Agradecemos à acadêmica Sandy Alves da Silva pelo apoio na apresentação do trabalho no XV SIC (UFT) e confecção do artigo.

Todos os autores declararam não haver qualquer potencial conflito de interesses referente a este artigo.

\section{REFERÊNCIAS}

ABNT. Associação Brasileira de Normas Técnicas. 2011. NBR ISO 17512-1: qualidade do solo: ensaio de fuga para avaliar a qualidade de solos e efeitos de substâncias químicas no comportamento. Parte 1: ensaio com minhocas (Eisenia fetida e Eisenia andrei). Rio de Janeiro.

ADAMS, S.M. Biological indicators of aquatic ecosystem stress. Am. Fish. Sc., 3, p. 104-112; 2002.

ADAPAR. Agência de defesa agropecuária do Paraná. 2018. Secretaria da Agricultura e do Abastecimento: DiPel $^{\circledR}$ WP. Disponível em: http://www.adapar.pr.gov.br/arquivos/File/defis/DFI/ Bulas/Inseticidas/dipel.pdf. Acesso 07/03/2018.

ALMEIDA, V.E.S.; CARNEIRO, F.F.; VILELA, N.J. Agrotóxicos em hortaliças: segurança alimentar, riscos socioambientais e políticas públicas para promoção da saúde. Tempus: Actas em saúde Coletiva. BrasíliaDF. v. 4, n. 4, p.84-99, 2009. 
ANDRÉA, M.M. O uso de minhocas como bioindicadores de contaminação de solos. Acta Zoologica Mexicana. n. 2, p. 95-107, 2010

CANDELLO, F.P. Comportamento de fuga de minhocas na presença do antimicrobiano sulfadiazina em solo. Campinas. Dissertação (Mestrado em Engenharia Civil). Universidade Estadual de Campinas- Faculdade de Engenharia Civil, Arquitetura e Urbanismo; 2014.

CÉSPEDES, C.L.; ALARCON, J. Biopesticidas de origen botánico, fitoquímicos y extractos de Celastraceae, Rhamnaceae y Scrophulariaceae. Boletín Latinoamericano y del Caribe de Plantas Medicinales y aromáticas, v. 10, n. 3, p. 175-181; 2011

CHINI, P. Uso de minhocas da espécie Eisenia fetida, como bioindicadores em solos contaminados com agrotóxicos. Palhoça, SC, (Trabalho de conclusão de curso - TCC) - Universidade do Sul de Santa Catarina - UNISUL; 2014.

ELSHAGHABEE, F.M.F.; ROKANA, N.; GULHANE, R.D.; SHARMA, C.; PANWAR, H. Bacillus as potential probiotics: status, concerns, and future perspectives. Frontiers in microbiology, v. 8 , Article 1490; 2017.

ISO - International Organization for Standardization. 1993. ISO 11268-1: soil quality: effects of pollutants on earthworms (Eisenia fetida): part 1: M: determination of acute toxicity using artificial soil substrate. Disponível em: https://www.iso.org/standard/53527.html.

ISO. International Organization for Standardization. 1998. ISO 11268-2: soil quality: effects of pollutants on earthworms (Eisenia fetida): part 2: determination of effects on reproduction. Disponível em: https://www.iso.org/standard/20993.html.

ISO - International Organization for Standardization, 2008. Soil quality - Avoidance test for determining the quality of soils and effects of chemicals on behaviour - Part 1: Test with earthworms (Eisenia fetida and Eisenia andrei). Disponível

em:

https://www.iso.org/standard/38402.html.

ISO. International Organization for Standardization. 2014. ISO 16387: soil quality effects of pollutants on Enchytraeidae (Enchytraeus sp.): determination of effects on reproduction and survival. Disponível em: https://www.iso.org/standard/30946.html.
KUEBUTORNYE, F.K.A.; ABARIKE, E.D.; LU, Y. $A$ review on the application of Bacillus as probiotics in aquaculture. Fish and Shellfish immunology. v. 87, p. $820-828 ; 2019$.

LOUREIRO, S.; SOARES, A.M.V.M.; NOGUEIRA, A.J.A. Terrestrial avoidance behavior tests as screening tool to assesss oil contamination. Environmental Pollution. v. 138, n ${ }^{\circ} 1$, p. 121-131; 2005.

MARIANO, W.S. Efeitos de biopesticida à base de Bacillus thuringiensis na histologia e fisiologia de Piaractus mesopotamicus e Arapaima gigas. Macapá. Tese de Doutorado. Universidade Federal do Amapá - UFAP. p. 84, 2017.

MODESTO, K.A. Efeitos de dois herbicidas à base de glifosato para um peixe neotropical, com enfoque nos biomarcadores bioquímicos. Londrina. Dissertação de Mestrado. Universidade Estadual de Londrina; 2009.

NIEMEYER, J.C.; CARNIEL, L. S. C.; DE SANTO, F. B.; SILVA, M.; KLAUBERGFILHO, O. Boric acid as reference substance for ecotoxicity tests in tropical artificial soil. Ecotoxicology, v. 27, n. 4, p. 395-401; 2018.

NIVA, C.C. Ecotoxicologia terrestre: métodos e aplicações dos ensaios com oligoquetas. Niva, C.C.; Brown, G.G. editores, Brasília (DF). Embrapa, 258p; 2019.

PRINCZ, J.; SCROGGINS, R. Toxicological comparis on of different soil test options - Earth worm lethality, avoid an ceand reproduction. Apresentação de poster, 13th Societyof Environmental Toxicology and chemistry (SETAC) Europe Meeting, Hamburg; 2003.

RAYMOND, B., JOHNSTON, P.R., NIELSENLEROUX, C., LERECLUS, D., CRICKMORE, N. Bacillus thuringiensis: an impotent pathogen? Trends Microbiol. v. 18, p. 189-194; 2010.

SISINNO, C.L.S.; BULUS, M.R.M.; RIZZO, A.C.; MOREIRA, J.C. Ensaio de comportamento com minhocas (Eisenia fetida) para avaliação de áreas contaminadas: resultados preliminares para contaminação por hidrocarbonetos. Revista JBSE, Rio Grande do Sul, v. 1, n. 2; 2006. 